\title{
ADAPTIVE CONTROL OF THE TUBULAR REACTOR WITH CO- AND COUNTER-CURRENT COOLING IN THE JACKET
}

\author{
Jiri Vojtesek and Petr Dostal \\ Faculty of Applied Informatics \\ Tomas Bata University in Zlin \\ Nad Stranemi 4511, 76005 Zlin, Czech Republic \\ E-mail: \{vojtesek,dostalp\}@fai.utb.cz
}

\section{KEYWORDS}

Tubular chemical reactor, Adaptive control, Countercurrent cooling, Co-current cooling,

\begin{abstract}
This paper deals with the adaptive control of the tubular chemical reactor as a typical member of nonlinear system with continuously distributed parameters. Although this system has negative control properties, proposed adaptive controller which uses external linear model and recursive identification provides good control results. This controller is designed with the use of polynomial approach which satisfies basic control requirements. The main benefit of the counter-current cooling compared with co the co-current can be found in the cooling effectiveness which is better from the control point of view too. The controller could be tuned via position of the closed-loop root.
\end{abstract}

\section{INTRODUCTION}

The role and usage of the simulation increases every day with the rapidly growing computer power and slumping costs of today's computers. Mathematical description is in this case very important and helps us with the constructing of the so called mathematical model (Luyben 1989). The computer simulation of systems described by the mathematical model then usually consist of static and dynamic analyses which describe the behaviour of the system in the steady-state and after the step change of the input variable. These analyses usually results in the optimal working point where the production is the highest or the costs are the lowest.

Tubular chemical reactor is tool frequently used in chemical industry for production of the several chemicals. This type of reactor belongs to the class of systems with distributed parameters because state variables here depend not only on the time variable but on the space variable too (Ingham et al. 2000). Configuration with one main pipe with several pipes inside used in this work offers cooling in the remaining space of the main pipe with the same or opposite direction to the flow direction of the reactant. This is in this paper called co- and counter-current cooling.

Controlling of such processes with conventional methods such as Ziegler-Nichols etc. could be problem mainly in the cases where the working point changes. This inconvenience should be overcome with the use of some of "new" control strategies such as adaptive control, predictive control etc. This work show process of the designing of the adaptive controller (Bobál et al. 2005). The adaptation is process known from the animals and plants which adapts their behaviour to the environment. This process means the loss of the energy collects information and experiences about the system. Adaptive approach here is based on the choice of the External Linear Model (ELM) of originally nonlinear system, parameters of which are estimate recursively and parameters of the controller are recomputed in each step according these identified ones.

The delta models (Mukhopadhyay et al. 1992) were used in ELM. Although these models belongs to the class of discrete-time models, parameters of such models approaches to the continuous-time ones for small sampling period (Stericker and Sinha 1993).

The polynomial approach together with the poleplacement method (Kučera 1993) which are used for the designing of the controller satisfy basic control requirements such as stability, disturbance attenuation or reference signal tracking.

All simulations were done in the mathematical simulation software Matlab, version 6.5.

\section{MATHEMATICAL MODEL OF THE PLANT}

As it is written above, this work compares two types of tubular chemical reactors varying in the direction of the cooling in the jacket.

The mathematical model of this system comes from material and heat balances inside the reactor. We consider ideal plug-flow tubular chemical reaction with a simple exothermic consecutive reaction $\mathrm{A} \rightarrow \mathrm{B} \rightarrow \mathrm{C}$ in the liquid phase (Dostál et al. 1996). Mathematical description of such process is very complex and so we introduce some simplifications. We neglect heat losses and conduction along the metal wall of the pipes, but heat transfer through the wall is consequential for a dynamic study. Furthermore, we expect that all densities, heat capacities and heat transfer coefficients are constant.

The graphical representation of the tubular chemical reactor can be found in Figure 1. 


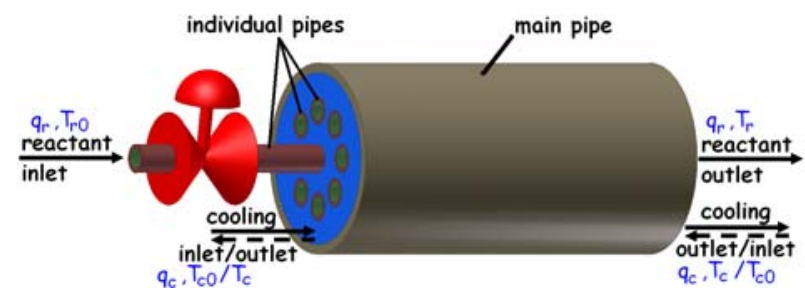

Figure 2: Tubular chemical reactor with co- (solid line) and counter-current (dashed line) cooling in the jacket

The mathematical model is in this case described by the set of five PDE derived from the balances inside the reactor:

$$
\begin{gathered}
\frac{\partial c_{A}}{\partial t}+v_{r} \cdot \frac{\partial c_{A}}{\partial z}=-k_{1} \cdot c_{A} \\
\frac{\partial c_{B}}{\partial t}+v_{r} \cdot \frac{\partial c_{B}}{\partial z}=k_{1} \cdot c_{A}-k_{2} \cdot c_{B} \\
\frac{\partial T_{r}}{\partial t}+v_{r} \cdot \frac{\partial T_{r}}{\partial z}=\frac{Q_{r}}{\rho_{r} \cdot c_{r p}}-\frac{4 \cdot U}{d_{1} \cdot \rho_{r} \cdot c_{p r}} \cdot\left(T_{r}-T_{w}\right) \\
\frac{\partial T_{w}}{\partial t}=\frac{4 \cdot\left[d_{1} U_{1}\left(T_{r}-T_{w}\right)+d_{2} U_{2}\left(T_{c}-T_{w}\right)\right]}{\left(d_{2}^{2}+d_{1}^{2}\right) \cdot \rho_{w} \cdot c_{p w}}
\end{gathered}
$$

These four PDE are common for both co- and countercurrent cooling. The difference can be found in the last PDE which comes from the heat balance of the cooling liquid.

This equation has for co-current cooling form:

$$
\frac{\partial T_{c}}{\partial t}+v_{c} \cdot \frac{\partial T_{c}}{\partial z}=\frac{4 \cdot n_{1} \cdot d_{2} \cdot U_{2} \cdot\left(T_{w}-T_{c}\right)}{\left(d_{3}^{2}-n_{1} \cdot d_{2}^{2}\right) \cdot \rho_{c} \cdot c_{p c}}
$$

and for counter-current cooling:

$$
\frac{\partial T_{c}}{\partial t}-v_{c} \cdot \frac{\partial T_{c}}{\partial z}=\frac{4 \cdot n_{1} \cdot d_{2} \cdot U_{2} \cdot\left(T_{w}-T_{c}\right)}{\left(d_{3}^{2}-n_{1} \cdot d_{2}^{2}\right) \cdot \rho_{c} \cdot c_{p c}}
$$

where $T$ is the temperature, $d$ represents diameters, $\rho$ are densities, $c_{p}$ means specific heat capacities, $U$ stands for the heat transfer coefficients, $n_{1}$ is a number of tubes and $L$ represents the length of the reactor. Index $(\bullet)_{r}$ means the reaction compound, $(\bullet)_{w}$ is for the metal wall of the pipes and $(\bullet)_{c}$ for the cooling liquid. Variables $v_{r}$ and $v_{c}$ are fluid velocities of the reactant and cooling liquid, respectively, as

$$
v_{r}=\frac{q_{r}}{f_{r}} ; \quad v_{c}=\frac{q_{c}}{f_{c}}
$$

where $q$ are flow rates and $f$ are constants

$$
f_{r}=n_{1} \cdot \frac{\pi \cdot d_{1}^{2}}{4} ; \quad f_{c}=\frac{\pi}{4} \cdot\left(d_{3}^{2}-n_{1} \cdot d_{2}^{2}\right)
$$

The reaction velocities, $k_{i}$, in equations (1) - (2) and equations are nonlinear functions of the temperature computed via the Arrhenius law:

$$
k_{j}=k_{0 j} \cdot \exp \frac{-E_{j}}{R \cdot T_{r}}, \text { for } j=1,2
$$

where $k_{0 j}$ represents pre-exponential factors, $E$ means activation energies and $R$ is a gas constant. $Q_{r}$ in the equation (3) is reaction heat computed as

$$
Q_{r}=h_{1} \cdot k_{1} \cdot c_{A}+h_{2} \cdot k_{2} \cdot c_{B}
$$

and $h_{j}$ is used for reaction enthalpies.

The mathematical model shows that this plant is $a$ nonlinear system with continuously distributed parameters (Ingham et al. 2000). Strong nonlinearity can be found in Equation (3), and the system is with distributed parameters because of the presence of the PDE where the state variable is related not only to the time variable, $t$, but the space variable, $z$, too.

In this case the initial conditions are $c_{A}(z, 0)=c_{A}{ }^{s}(z)$, $c_{B}(z, 0)=c_{B}^{s}(z), T_{r}(z, 0)=T_{r}^{s}(z), T_{w}(z, 0)=T_{w}^{s}(z)$ and $T_{c}(z, 0)=T_{c}^{s}(z)$ and boundary conditions $c_{A}(0, t)=c_{A 0}(t)$, $c_{B}(0, t)=c_{B 0}(t)=0, T_{r}(0, t)=T_{r 0}(t), \mathrm{T}_{\mathrm{c}}(0, t)=T_{c 0}(t)$ for the co-current cooling and $T_{c}(\mathrm{~L}, \mathrm{t})=T_{c L}(t)$ for the countercurrent cooling.

Fixed parameters of the reactor (Dostál et al. 1996) are shown in the following table:

Table 1: Fixed parameters of the tubular reactor

\begin{tabular}{|cc|}
\hline$d_{1}=0.02 \mathrm{~m}$ & $c_{p c}=4.18 \mathrm{~kJ} \cdot \mathrm{kg}^{-1} \cdot \mathrm{K}^{-1}$ \\
$d_{2}=0.024 \mathrm{~m}$ & $U_{1}=2.8 \mathrm{~kJ} \cdot \mathrm{m}^{-2} \cdot \mathrm{K}^{-1} \cdot \mathrm{s}^{-1}$ \\
$d_{3}=1 \mathrm{~m}$ & $U_{2}=2.56 \mathrm{~kJ} \cdot \mathrm{m}^{-2} \cdot \mathrm{K}^{-1} \cdot \mathrm{s}^{-1}$ \\
$n_{1}=1200$ & $k_{10}=5.61 \times 10^{16} \mathrm{~s}^{-1}$ \\
$L=6 \mathrm{~m}$ & $k_{20}=1.128 \times 10^{16} \mathrm{~s}^{-1}$ \\
$q_{r}=0.15 \mathrm{~m}^{3} \cdot \mathrm{s}^{-1}$ & $E_{1} / R=13477 \mathrm{~K}$ \\
$q_{c}=0.275 \mathrm{~m}^{3} \cdot \mathrm{s}^{-1}$ & $E_{2} / R=15290 \mathrm{~K}$ \\
$\rho_{r}=985 \mathrm{~kg} \cdot \mathrm{m}^{3}$ & $h_{1}=5.8 \times 10^{4} \mathrm{~kJ} \cdot \mathrm{kmol}^{-1}$ \\
$\rho_{w}=7800 \mathrm{~kg} \cdot \mathrm{m}^{3}$ & $h_{2}=1.8 \times 10^{4} \mathrm{~kJ} \cdot \mathrm{kmol}^{-1}$ \\
$\rho_{c}=998 \mathrm{~kg} \cdot \mathrm{m}^{3}$ & $c_{A 0}{ }^{3}=2.85 \mathrm{kmol} \cdot \mathrm{m}^{-3}$ \\
$c_{p r}=4.05 \mathrm{~kJ} \cdot \mathrm{kg}^{-1} \cdot \mathrm{K}^{-1}$ & $T_{r 0}{ }^{s}=323 \mathrm{~K}$ \\
$c_{p w}=0.71 \mathrm{~kJ} \cdot \mathrm{kg}^{-1} \cdot \mathrm{K}^{-1}$ & $T_{c 0}{ }^{\mathrm{s}}=293 \mathrm{~K}$ \\
\hline
\end{tabular}

\section{STEADY-STATE AND DYNAMIC ANALYSES}

The steady-state and dynamic analyses are important parts in the design of the controller especially in the simulation cases. Results of these analyses gives us overview of the system's static and dynamic behaviour. From the mathematical point of view, the static analysis means solving of the set of PDE (1) - (6) for the time $t \rightarrow \infty$, which means that all derivatives with respect to time are equal to zero. But there are still derivatives with respect to axial variable.

These derivatives can be replaced from the mathematical point of view by the first back (co-current cooling) and forward (counter-current cooling) differences :

$$
\begin{gathered}
\left.\frac{d x}{d z}\right|_{z=z_{i}} \approx \frac{x(i)-x(i-1)}{h_{z}}, \text { for } i=1,2, \ldots, n \\
\left.\frac{d x}{d z}\right|_{z=z_{j}} \approx \frac{x(j+1)-x(j)}{h_{z}}, \text { for } j=n, n-1, \ldots, 0
\end{gathered}
$$

where $x$ is a general variable, $h_{z}$ is an optional size of the step in axial direction. The defined input boundary conditions, $x_{0}$, for $i=1$ are equal to boundary conditions 
$x(0)$. If the reactor is divided into $N_{z}$ equivalent parts, the discretization step is

$$
h_{z}=\frac{L}{N_{z}}
$$

where $L$ denotes the length of the reactor and $N_{z}=100$. The steady-state analysis was performed for the different volumetric flow rate of the cooling $q_{c}{ }^{s}=<0.1$; $0.35>\left[\mathrm{m}^{3} \cdot \mathrm{s}^{-1}\right]$ in the jacket and the results for both coand counter-current cooling are shown in Figure 3 and Figure 4. It can be clearly seen that counter-current cooling results in high nonlinearity whereas in cocurrent cooling the variables are close to linear course.

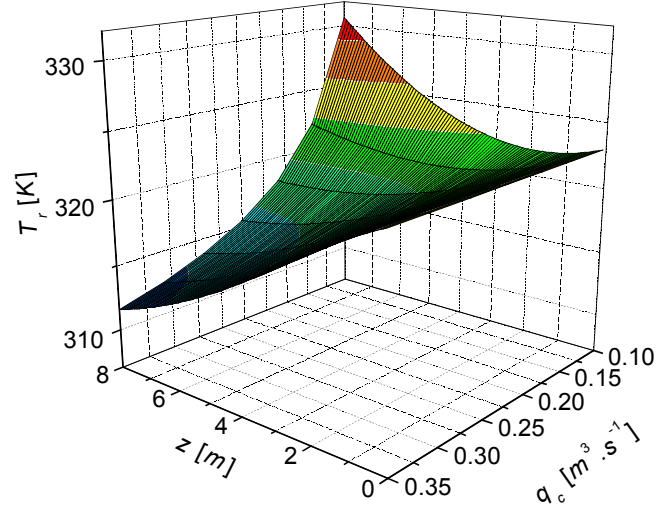

Figure 3: Steady-state analysis of the temperature of the reactant $T_{r}^{s}$ for co-current cooling

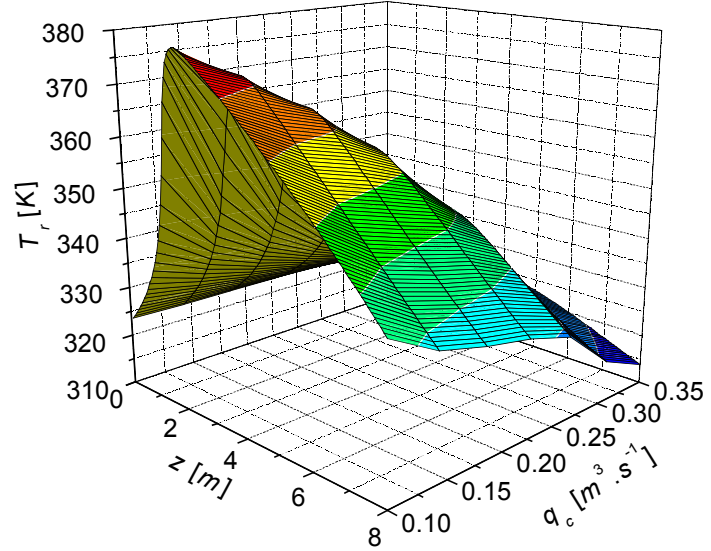

Figure 4: Steady-state analysis of the temperature of the reactant $T_{r}^{s}$ for counter-current cooling

The steady-state analysis results in the working point which is in this case defined by the volumetric flow rate of the reactant $q_{r}^{s}=0.150 \mathrm{~m}^{3} \cdot \mathrm{s}^{-1}$ and the volumetric flow rate of the coolant $q_{c}^{s}=0.275 \mathrm{~m}^{3} . \mathrm{s}^{-1}$. These variables are later used for dynamic analysis and simulation of the control.

The dynamic analysis is the next step after the steadystate analysis. It examines the behaviour after the step change of one of the input variables. Because the set of PDE (1) - (6) has derivatives with the respect to axial variable $z$, the discretization described by equations (11) must be used. The set of PDE is then transformed to a set of ODE which is then solved by the standard RungeKutta's method.

This analysis was done for four step changes $\pm 20 \%$ and $\pm 10 \%$ of the volumetric flow rate of the cooling liquid, $\Delta q_{c}^{s}$, i.e. $-0.055(-20 \%),-0.0275(-10 \%), 0.0275$ $(10 \%), 0.055(20 \%) \mathrm{m}^{3} . \mathrm{s}^{-1}$. The output variable $y(t)$ illustrate the difference between the actual values of the reactive temperature, $T_{r}$, at the end of the reactor $(z=L)$ and its steady-state value $T_{r}^{s}$. These input and output variables should be mathematically described as

$$
\begin{gathered}
u(t)=\frac{q_{c}(t)-q_{c}^{s}}{q_{c}^{s}} \cdot 100[\%] \\
y(t)=T_{r}(t, L)-T_{r}^{s}(L)[K]
\end{gathered}
$$

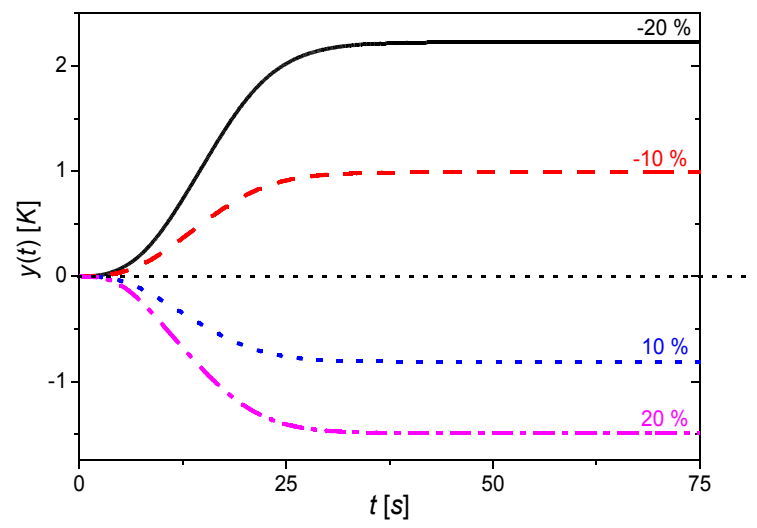

Figure 5: Output responses for various step changes $\Delta q_{c}{ }^{s}$ and co-current cooling

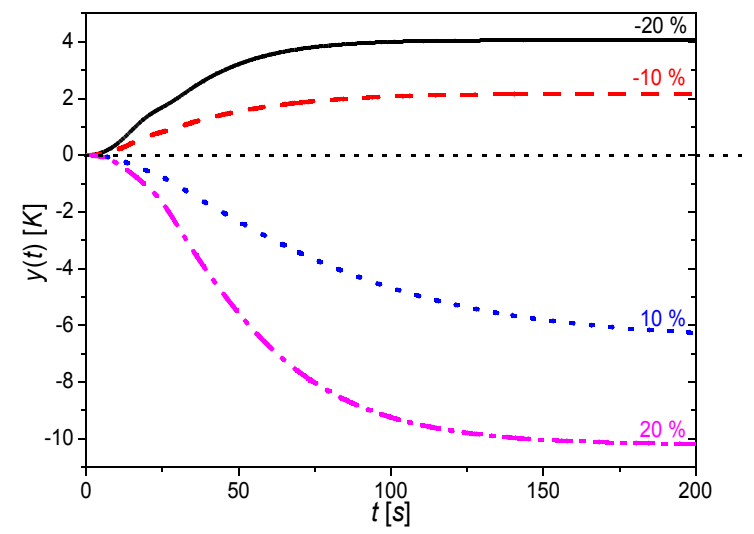

Figure 6: Output responses for various step changes $\Delta q_{c}^{s}$ and counter-current cooling

The output responses for both cooling techniques displayed in Figure 5 and Figure 6 shows that this output should be expressed by second order transfer function with relative order one for the case of nonminimum phase behaviour:

$$
G(s)=\frac{b(s)}{a(s)}=\frac{b_{1} s+b_{0}}{s^{2}+a_{1} s+a_{0}}
$$

The last graphs in Figure 7 and Figure 8 compares dynamic behaviour for co- and counter-current cooling. The result is obvious - cooling capability of the 
counter-current cooling is at least twice bigger than for the co-current cooling with the same input step change. This feature was proofed and developed in deep detail in (Vojtěšek et al. 2006).

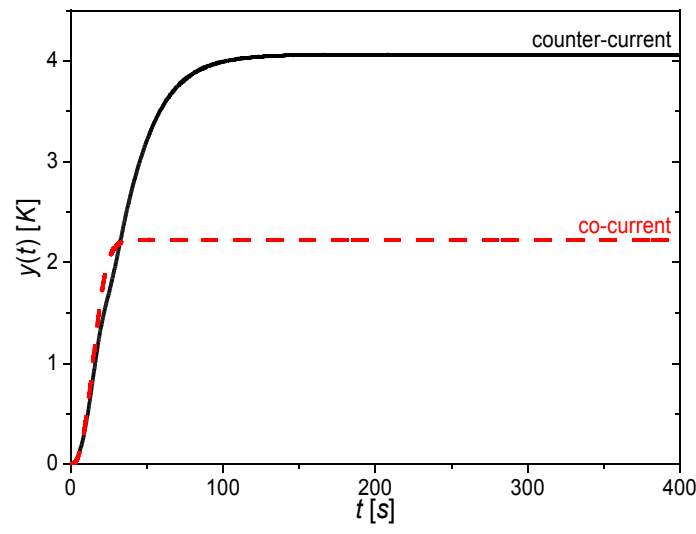

Figure 7: Comparison of co-current and countercurrent cooling for step change $\Delta q_{c}{ }^{s}=-20 \%$

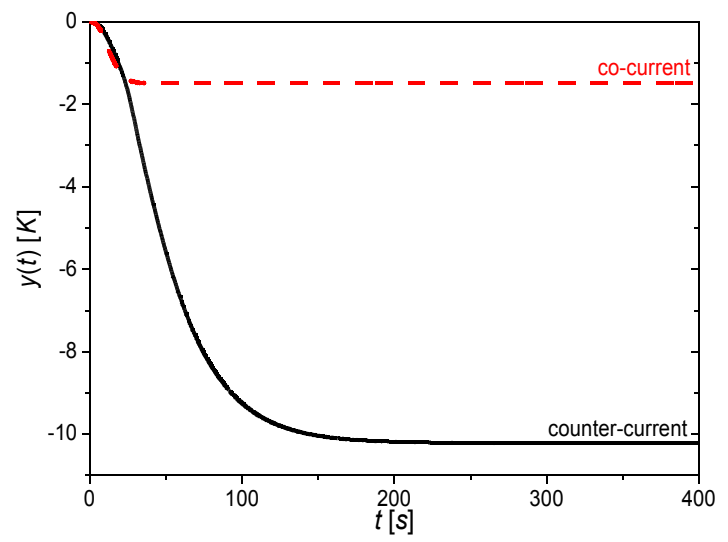

Figure 8: Comparison of co-current and countercurrent cooling for step change $\Delta q_{c}{ }^{s}=+20 \%$

\section{ADAPTIVE CONTROL}

As it is written above, results from the dynamic analysis helps with the choice of the External Linear Model (ELM) (14). The adaptive approach here is based on the recursive parameter identification of the ELM and parameters of the controller are recomputed according to the estimated parameters in every step too (Bobál et al. 2005).

The adaptive controller is designed via polynomial synthesis (Kučera 1993) which fulfills basic control requirements and it can be used for systems with negative control properties.

The basic control configuration with one degree-offreedom displayed in Figure 9 was used.

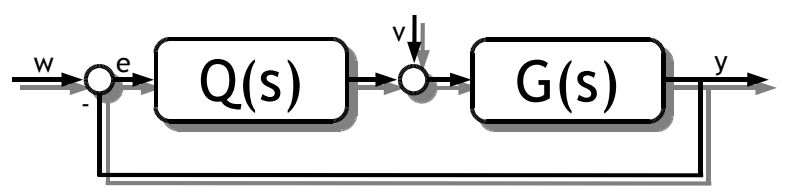

Figure 9: One degree-of-freedom control configuration
Block $Q$ in Figure 9 represents the transfer function of the controller, $G$ denotes the transfer function of the plant, $w$ is the reference signal, $e$ is used for the control error, $v$ is the disturbance at the input to the system, $u$ determines the input variable, and finally $y$ is the output variable. Polynomials $a(s)$ and $b(s)$ in the transfer function (14) are commensurable polynomials in complex $s$-plane. The realizability condition is fulfilled if the system is proper, i.e. $\operatorname{deg} a(s) \geq \operatorname{deg} b(s)$. The transfer function of the controller then is

$$
\tilde{Q}(s)=\frac{q(s)}{s \cdot \tilde{p}(s)}
$$

where polynomials $q(s)$ and $\tilde{p}(s)$ are computed from the Diophantine equation

$$
a(s) \cdot s \cdot \tilde{p}(s)+b(s) \cdot q(s)=d(s)
$$

by the method of uncertain coefficients which compares coefficients of individual $s$-powers. The polynomial $d(s)$ on the right side of (16) is stable optional polynomial which fulfills the stability of the controller.

Degrees of the polynomials $q(s), \tilde{p}(s)$ and $d(s)$ are for the transfer function (14)

$$
\begin{gathered}
\operatorname{deg} \tilde{p}(s) \geq \operatorname{deg} a(s)-1=1 \\
\operatorname{deg} q(s)=\operatorname{deg} a(s)=2 \\
\operatorname{deg} d(s)=\operatorname{deg} a(s)+\operatorname{deg} \tilde{p}(s)+1=4
\end{gathered}
$$

which means that the transfer function of the controller in Equation (15) could be rewritten to form

$$
\tilde{Q}(s)=\frac{q(s)}{s \cdot \tilde{p}(s)}=\frac{q_{2} s^{2}+q_{1} s+q_{0}}{s \cdot\left(p_{1} s+p_{0}\right)}
$$

The optional polynomial $d(s)$ is in our case

$$
d(s)=m(s) \cdot n(s)
$$

where $m(s)$ is $m(s)=(s+\alpha)^{2}$ for $\alpha>0$ and $n(s)$ comes from the spectral factorization of $a(s)$ :

$$
n^{*}(s) \cdot n(s)=a^{*}(s) \cdot a(s) \Rightarrow \quad \begin{aligned}
& n_{0}=\sqrt{a_{0}^{2}} \\
& n_{1}=\sqrt{a_{1}^{2}+2 n_{0}-2 a_{0}}
\end{aligned}
$$

Polynomials $a(s)$ and $b(s)$ in (14) and (18) are known from the recursive identification.

The delta models were used for the estimation model. Although the delta models belong to the class of discrete-time models, parameters of such model approach to the continuous-time model for small sampling period (Stericker and Sinha 1993).

The transfer function $G(s)$ in (14) could be rewritten to the form of differential equation:

$$
\begin{aligned}
y_{\delta}(k) & =-a^{\prime}{ }_{1} y_{\delta}(k-1)-a^{\prime}{ }_{0} y_{\delta}(k-2)+ \\
& +b^{\prime}{ }_{1} u_{\delta}(k-1)+b^{\prime}{ }_{0} u_{\delta}(k-2)
\end{aligned}
$$

which is in the vector form

$$
y_{\delta}=\theta_{\delta}^{T}(k) \cdot \phi_{\delta}(k-1)
$$

and the vector of the parameters, $\boldsymbol{\theta}_{\delta}$, and the data vector, $\boldsymbol{\varphi}_{\delta}$, are then

$$
\begin{gathered}
\theta_{\delta}(k)=\left[a^{\prime}{ }_{1,} a^{\prime}{ }_{0}, b^{\prime}{ }_{1,} b^{\prime}{ }_{0}\right]^{T} \\
\phi_{\delta}(k-1)=\left[-y_{\delta}(k-1),-y_{\delta}(k-2), \ldots\right. \\
\left.\ldots, u_{\delta}(k-1), u_{\delta}(k-2)\right]^{T}
\end{gathered}
$$




$$
\begin{gathered}
y_{\delta}(k)=\frac{y(k)-2 y(k-1)+y(k-2)}{T_{v}^{2}} ; \\
y_{\delta}(k-1)=\frac{y(k-1)-y(k-2)}{T_{v}} ; \quad y_{\delta}(k-2)=y(k-2) \\
u_{\delta}(k-1)=\frac{u(k-1)-u(k-2)}{T_{v}} ; \quad u_{\delta}(k-2)=u(k-2)
\end{gathered}
$$

The goal of the identification is to estimate vector of parameters $\boldsymbol{\theta}_{\delta}$ in ARX model (22) from the previous values of the input and output variables in the time intervals remote by sampling period $T_{\underline{\underline{v}}}$. The recursive least-squares method with exponential forgetting was used for identification in this work (Fikar and Mikleš 1999).

\section{SIMULATION RESULTS}

The input and output variables, initial values and settings in the simulation experiments are the same as in the dynamic analysis described by the Equation (13). The simulation time is $T_{f}=10000$ seconds and 5 different step changes were done during this time.

The sampling time for counter-current cooling was $T_{v}=1.5 \mathrm{~s}$ and simulations were done for three values of the parameter $\alpha=0.007,0.01$ and 0.02 . The results are shown in Figure 10 and 11.

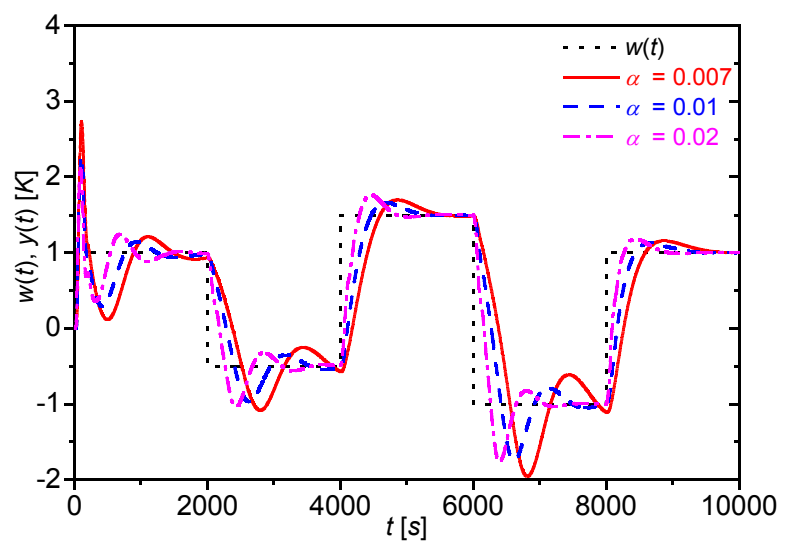

Figure 10: The course of the output variable $y(t)$ for different parameter $\alpha$ for counter-current cooling

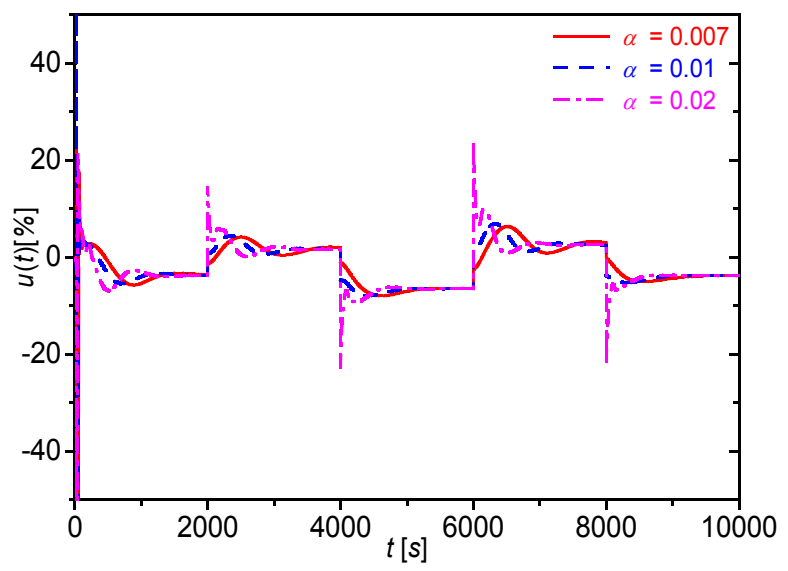

Figure 11: The course of the input variable $u(t)$ for different parameter $\alpha$ for counter-current cooling
It can easily seen from the figures that increasing value of parameter $\alpha$ results mainly in quicker output response. On the other hand, low value of $\alpha$ produces smoother course of the input variable $u(t)$ which is better from the practical point of view. The input variable is in our case represented by the volumetric flow rate of the coolant which could be reduced by the valve and shocking twists of the valve could demage or destroy it.

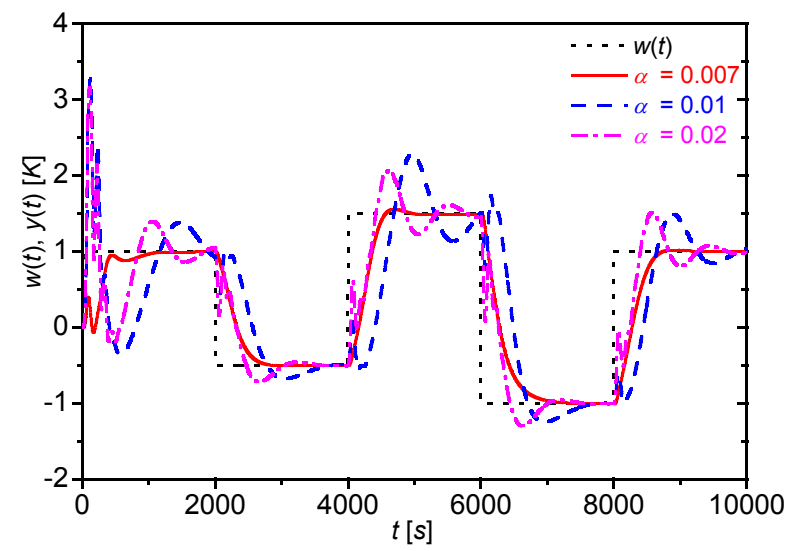

Figure 12: The course of the output variable $y(t)$ for different parameter $\alpha$ for co-current cooling

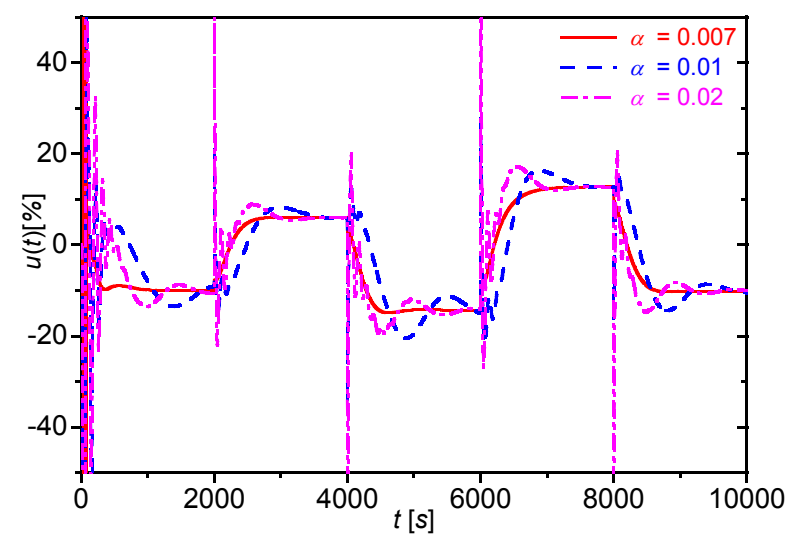

Figure 13: The course of the input variable $u(t)$ for different parameter $\alpha$ for co-current cooling

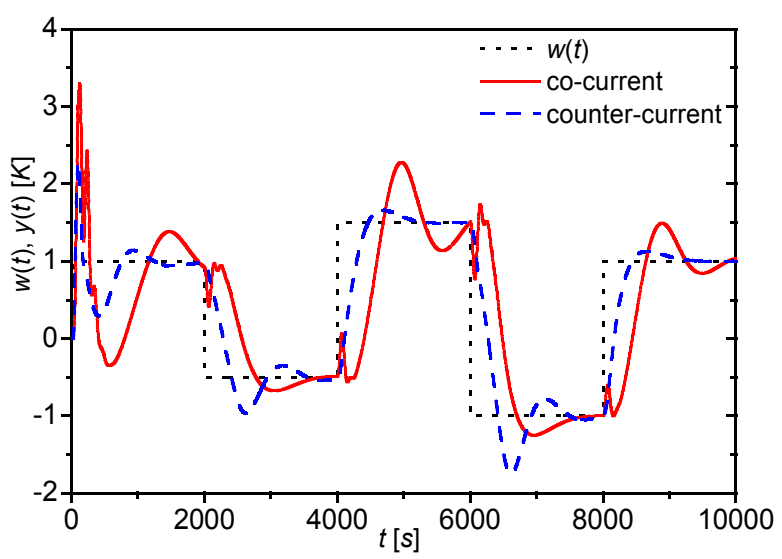

Figure 14: Comparison of the output response of the coand counter- current cooling for $\alpha=0.01$ 
The control analysis for co-current cooling was performed for the same settings as for counter-current cooling for the reason of comparability but the results for sampling period were unacceptable and it was decreased to its half value, i.e. $T_{v}=0.75 \mathrm{~s}$. The results presented in Figure 12 and 13 shows the same effect of the value as for counter-current cooling.

Figures 14, 15, 16 and 17 clearly shows the main benefits of the counter-current cooling. This type of cooling has better effectiveness which reflects mainly in the course of the input variable $u(t)$ which is smoother and its value is lower than for co-current cooling. The output variable $y(t)$ has smoother and quicker course too.

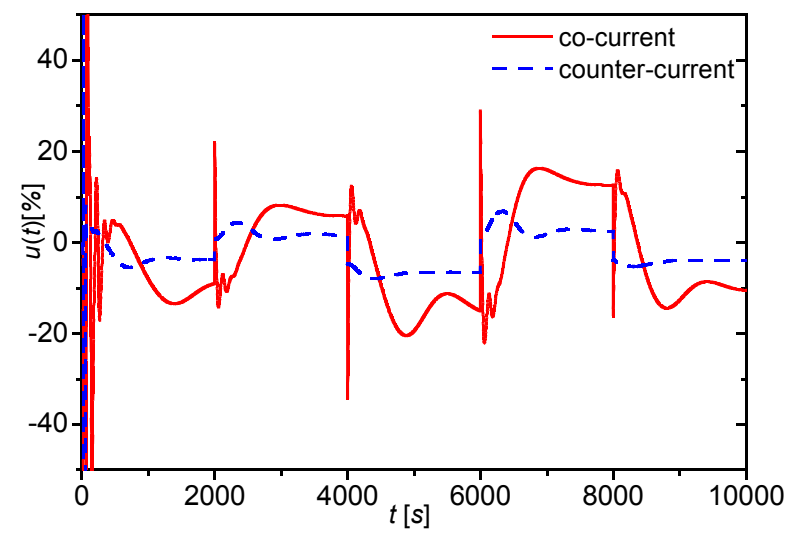

Figure 15: The course of the input variable for the coand counter- current cooling, $\alpha=0.01$

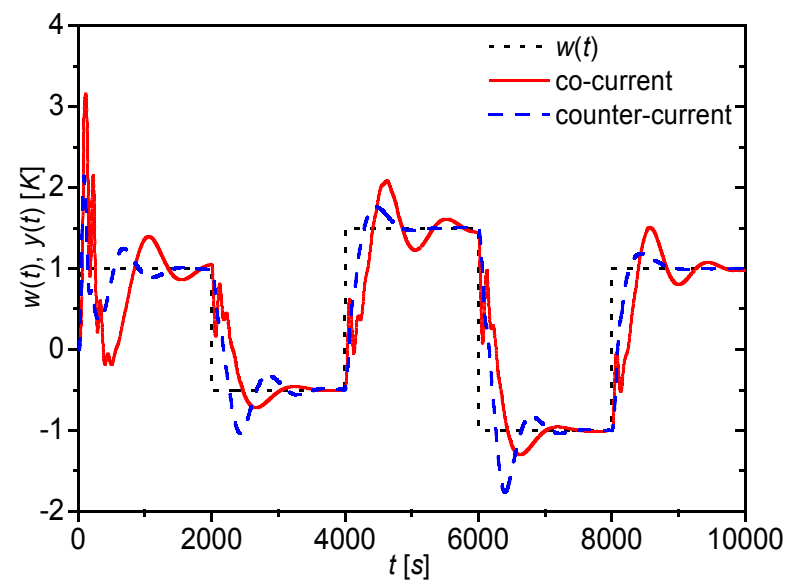

Figure 16: Comparison of the output response of the coand counter- current cooling for $\alpha=0.02$

Because we wanted to have some mathematical tool to compare obtained results, the control quality criteria $S_{u}$ and $S_{y}$ were introduced:

$$
\begin{aligned}
S_{u} & =\sum_{i=2}^{N}(u(i)-u(i-1))^{2}[-] ; \quad \text { for } N=\frac{T_{f}}{T_{v}} \\
S_{y} & =\sum_{i=1}^{N}(w(i)-y(i))^{2}\left[K^{2}\right] ;
\end{aligned}
$$

Values of these criterions clearly shows benefits of the counter-current cooling in the jacket which are lower than for co-current cooling in more cases. The values for both types of cooling are displayed in Table 2 and highlighted in Figures 18 and 19.

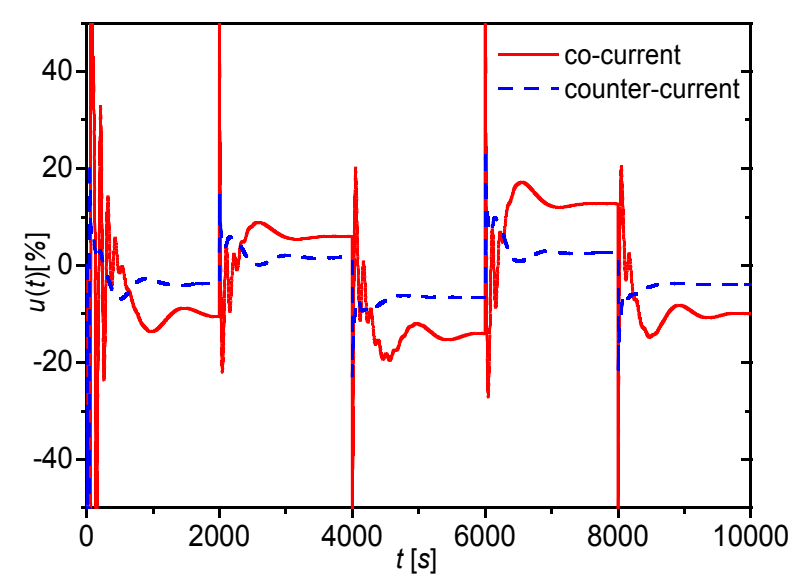

Figure 17: The course of the input variable for the coand counter- current cooling, $\alpha=0.02$

\begin{tabular}{|c|c|c|c|c|}
\hline & \multicolumn{2}{|c|}{ Co-current cooling } & \multicolumn{2}{|c|}{$\begin{array}{l}\text { Counter-current } \\
\text { cooling }\end{array}$} \\
\hline & $S_{u}[-]$ & $S_{y}[-]$ & $S_{u}[-]$ & $S_{y}[-]$ \\
\hline$\alpha_{1}=0.007$ & 320680.51 & 2179.02 & 31779.06 & 3029.87 \\
\hline$\alpha_{1}=0.01$ & 11916.77 & 5077.97 & 31107.32 & 1922.40 \\
\hline$\alpha_{1}=0.02$ & 38361.72 & 1975.38 & 10522.22 & 1161.74 \\
\hline
\end{tabular}

Table 2: Control quality criteria $S_{u}$ and $S_{y}$

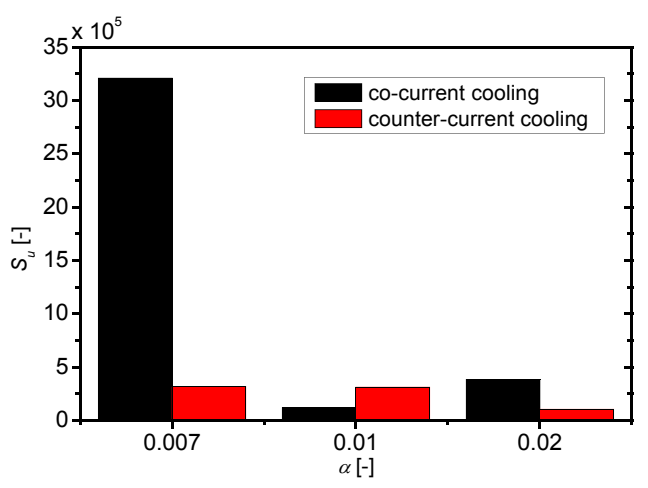

Figure 18: Values of the control quality criterion $S_{u}$ for co- and counter-current cooling

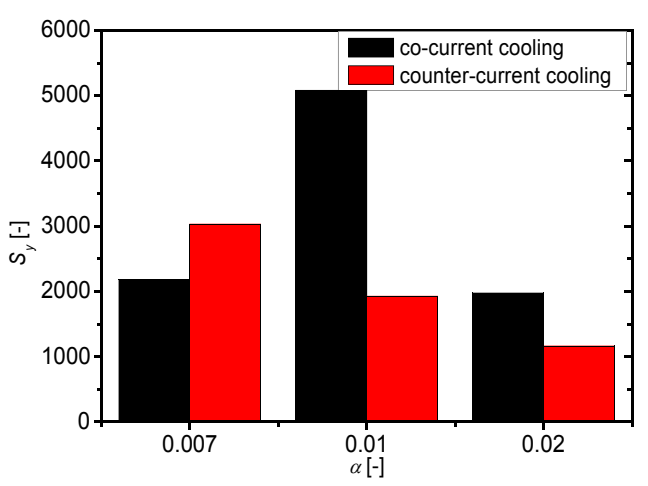

Figure 19: Values of the control quality criterion $S_{y}$ for co- and counter-current cooling 


\section{CONCLUSIONS}

The goal of this contribution was mainly to show simulation results of the adaptive control used for the controlling of the reactant's temperature via volumetric flow rate of the coolant in the jacket. Used adaptive approach which estimates parameters of the ELM produces good control results although the system has negative control properties such as nonlinearity, time delay etc. The controller could be tuned by the choice of the parameter $\alpha$ which is position of the root. The increasing value of $\alpha$ results in quicker output response but bigger overshoots. The comparison of co-current and counter-current cooling in the jacket clearly shows that cooling with opposite direction to the flow of the reactant has better effectiveness than cooling which flows with the same direction as the reactant. Another advantage could be found in sampling period which is twice bigger for the counter-current cooling than for cocurrent with comparably good results.

\section{REFERENCES}

Bobál, V., Böhm, J., Fessl, J. Macháček, J. 2005. Digital Selftuning Controllers: Algorithms, Implementation and Applications. Advanced Textbooks in Control and Signal Processing. Springer-Verlag London Limited

Dostál, P., Prokop, R., Prokopová, Z., Fikar, M. 1996. "Control design analysis of tubular chemical reactors". Chem. Papers, 50, 195-198

Fikar, M., Mikleš, J. 1999. System identification [in Slovak]. STU Bratislava

Ingham, J., Dunn, I. J., Heinzle, E., Přenosil, J. E. 2000. Chemical Engineering Dynamics. An Introduction to Modelling and Computer. Simulation. Second, Completely Revised Edition, VCH Verlagsgesellshaft, Weinheim.

Kučera, V. 1993. "Diophantine equations in control - A survey". Automatica, 29, 1361-1375

Luyben, W. L. 1989. Process Modelling, Simulation and Control for Chemical Engineers. McGraw-Hill, New York
Mukhopadhyay, S., Patra, A. G., Rao, G. P. 1992. "New class of discrete-time models for continuous-time systems". International Journal of Control, vol.55, 1161-1187

Stericker, D.L., Sinha, N.K. 1993. "Identification of continuous-time systems from samples of input-output data using the $\delta$-operator". Control-Theory and Advanced Technology, vol. 9, 113-125

Vojtěšek, J., Dostál, P., Matušů, R. 2006. "Effect of Co- and Counter-current Cooling in Tubular Reactor", In: Proc. 7th International Scientific-Technical Conference Process Control 2006. Kouty n. Desnou. Czech Republic.

\section{ACKNOWLEDGMENT}

This work was supported by the Ministry of Education of the Czech Rep. under grant No. MSM 7088352101.

\section{AUTHOR BIOGRAPHIES}

JIRI VOJTESEK was born in Zlin, Czech Republic and studied at the Tomas Bata University in Zlin, where he got his master degree in chemical and process engineering in 2002. He has finished his Ph.D. focused on Modern control methods for chemical reactors in 2007. His contact is vojtesek@fai.utb.cz.

PETR DOSTAL studied at the Technical University of

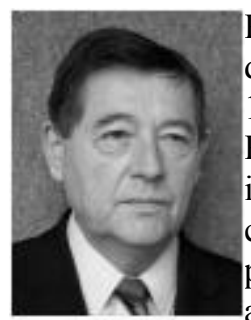
Pardubice. $\mathrm{He}$ obtained his $\mathrm{PhD}$. degree in Technical Cybernetics in 1979 and he became professor in Process Control in 2000. His research interest are modeling and simulation of continuous-time chemical processes, polynomial methods, optimal, adaptive and robust control. You can contact him on email address dostalp@fai . utb.cz. 